\title{
Zymomonas mobilis LEVANSUKRAZ ENZIMMINİN LEVAN ÜRETİMİNDE KULLANILMASI
}

\author{
Güler Sözgen ${ }^{1}$, Gökçenaz Özdoğan², Burcu Kaplan Türköz ${ }^{2 *}$ \\ ${ }^{1}$ Ege Üniversitesi Fen Bilimleri Enstitüsü, İzmir, Türkiye \\ ${ }^{2}$ Ege Üniversitesi Mühendislik Fakültesi Gıda Mühendisliği Bölümü, İzmir, Türkiye
}

Geliş / Received: 09.08.2018; Kabul / Accepted: 22.11.2018; Online bask1 / Published online: 07.12.2018

Sözgen, G., Özdoğan, G., Kaplan Türköz, B. (2018). Zymomonas mobilis levansukraz enziminin levan üretiminde kullanılması. GIDA (2018) 43 (6): 1061-1074 doi: 10.15237/gida.GD18087

Sözgen, G., Özdoğan, G., Kaplan Türköz, B. (2018). Use of Zymomonas mobilis levansucrase in levan production. GIDA (2018) 43 (6): 1061-1074 doi: 10.15237/gida.GD18087

\section{ÖZ}

Levan gıda, kozmetik ve ilaç sanayi gibi birbirinden farklı endüstrilerde kullanım alanına sahip bir fruktoz polimeridir. Levansukrazlar sakkarozu substrat olarak kullanarak fruktoz polimerleri oluşumunu katalizleyen enzimlerdir. Bakteriler tarafindan hücre dışına salgilanan levansukrazlar bakterinin yüksek sakkaroz konsantrasyonunda levan ve/veya fruktooligosakkarit polimerlerini sentezlemesini sağlar. Bu çalışmada Zymomonas mobilis NRRL B-14023 kullanilarak levansukraz enziminin üretilmesi ve levan polimeri üretme koşulları incelenmiştir. Yapılan çalşmada $Z$. mobilis levansukrazı üretilmiş ve ham enzimin levan aktivitesi gösterilmiştir. Levansukraz, Z. mobilis B-14023 hücreleri tarafindan 36 saat boyunca $30.3{ }^{\circ} \mathrm{C}$ 'de $159 \mathrm{~g} / \mathrm{L}$ sakkaroz, pH 4.91 ortamında statik kültürde üretilmiştir. Levansukrazın levan üretimi için optimum inkübasyon süresi ve sıcaklığı 24 saat ve $25{ }^{\circ} \mathrm{C}$ olarak bulunduktan sonra aktiviteye etki eden faktörler araştırlmıştrr. Artan $\mathrm{NaCl}$ konsantrasyonunda levan üretiminde azalma olduğu görülmüştür. Ayrıca $10 \mathrm{mM}$ EDTA ve $\mathrm{MgCl}_{2}$ varlı̆̆ında enzimin levan üretim aktivitesinde azalma olduğu bulunmuştur. Sonuç olarak $Z$. mobilis NRRL B-14023 levansukrazı ile ortalama $62.42 \mathrm{~g} / \mathrm{L}$ levan üretilmiştir.

Anahtar kelimeler: Zymomonas mobilis, Levansukraz, Levan

\section{USE of Zymomonas mobilis LEVANSUCRASE IN LEVAN PRODUCTION}

\begin{abstract}
Levan has a wide range of uses in different industries such as food, cosmetics and pharmaceutical. Levansucrases are enzymes, which catalyze the formation of fructose polymers using sucrose as substrate. Levansucrases are produced and secreted by bacteria and enable them to synthesize levan/fructooligosaccharides in medium containing high sucrose concentrations. In this study, Zymomonas mobilis levansucrase was produced and its levan activity was investigated. Levansucrase was produced by Z. mobilis NRRL B-14023 cells in static culture in medium with $159 \mathrm{~g} / \mathrm{L}$ sucrose, $\mathrm{pH} 4.91$ at $30.3{ }^{\circ} \mathrm{C}$ for $36 \mathrm{~h}$. The optimum incubation time, temperature of crude enzyme for levan production were found as $24 \mathrm{~h}$ and $25^{\circ} \mathrm{C}$. The levan production of levansucrase decreased with increasing $\mathrm{NaCl}$ concentrations. Furthermore the presence of $10 \mathrm{mM}$ EDTA and $\mathrm{MgCl}_{2}$ showed an inhibitory effect on levan production. As a result, on average $62.42 \mathrm{~g} / \mathrm{L}$ levan was produced using $Z$. mobilis NRRL B-1423 levansucrase.
\end{abstract}

Keywords: Zymomonas mobilis, Levansucrase, Levan

\footnotetext{
*Yazışmalardan sorumlu yazar / Corresponding author;

$\triangle$ burcu.kaplan.turkoz@ege.edu.tr O(+90) $2323113011 \quad$ 岛(+90) 2323114831
} 


\section{GİRİ̧̧}

Fruktanlar sakkarozdan türetilen fruktoz polimerleridir (Ritsema ve Smeekens, 2003). Fruktanlar gida endüstrisinde oldukça geniş kullanım alanına sahiptir. İnülin tipi fruktanlar tatlandırıc1, yağ ikamesi, tekstür düzeltici, stabilizatör ve jelleştirici olarak, ekmekçilikte, pastacilikta, bebek mamalarında, dondurma ve tatllarda kullanilmaktadır (Roberfroid, 2000). Levan tipi fruktanlar ise hem suda hem yağda çözünebilir olmaları, yuiksek molekül ağırlığ1 ve düşük viskoziteye sahip olmaları, oda sıcaklığında su içinde şişmemeleri gibi bir çok özellikleri sayesinde gıda endüstrisinde jelleştirici ajan, emulgatör, stabilizatör ve kıvam arttırıcı olarak kullanılabilme potansiyeline sahiptir (Arvidson vd., 2006; Srikanth vd., 2015a). Levan, ana zincire D- fruktofuranosil halkalarının $\beta$ - $(2,6)$ bağları ile bağlanmasindan oluşan doğal bir fruktoz polimeridir (Bekers vd., 2005) (Şekil 1).

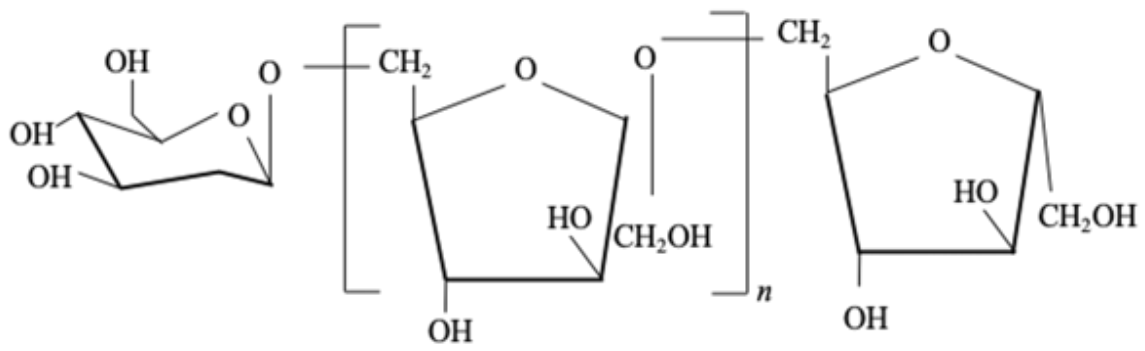

Şekil 1: Levan polimerinin kimyasal yapısı.

Figure 1: Chemical structure of levan polymer.

Levan polimerinin ticari üretiminin ABD'de 1930'lu yıllarda başladığ1 bildirilmiştir (Srikanth vd., 2014). Levan, g1da, kozmetik, ilaç gibi birbirinden farklı endüstrilerde kullanım alanı bulmuştur (Ergene ve Avc1, 2016). Levan kimyasal özellikleri sayesinde diğer moleküllerle kovalent bağ yapabilir ve fonksiyonel polimerlerin olușumuna olanak sağlar. Örneğin levan fosfatın bu özelliği ile yağ ikamesi olarak kullanılabileceği bildirilmiştir (Roberts ve Garegg, 1998). Levanın yağ ikamesi olarak kullanılmasında yüksek moleküler ağırllğı ile tat reseptörleri tarafindan alg1lanamayacak kadar büyük olması ve uçuculuk özelliğinin algılanabilir seviye için çok düşük olması da avantaj sağlamaktadır (Xiao vd., 2014). Ekmek ile ilgili yapılan bir çalışmada levanın mikrojel oluşturmasının raf ömrünün uzamasına etkili olduğu bulunmuştur. Buğday ekmeğine en az \%1 oraninda levan eklendiğinde kontrole kiyasla \%18-26 oranında daha yumuşak ekmek elde edildiği gösterilmiştir (Jakob vd., 2012). Levanın biyobozunur ambalaj malzemesi olarak da kullanılabileceği bildirilmektedir. Levanın yapısında uzun esnek parçalar bulunmadığı için levan polimerinden yapılan filmler kullanım için çok kırılgandır ancak kil veya diğer plastikleștiricilerle birlikte kullanılmasıyla bu soruna çözüm bulunmuştur (Vijayendra ve Shamala, 2014). Bütün bu özelliklerinin yanında levan ayrıca prebiyotik özellik de göstermektedir (Ki-Hyo vd., 2003). Anti-irritan, antioksidan ve antienflamatuar aktiviteleri de olduğu için levan tıbbi açıdan da değerli bir polimerdir (Öner vd., 2016).

Levan üretimi mikrobiyal fermantasyon ile yapilabilmektedir. Zymomonas mobilis fermantasyonu sonrasi elde edilen üst fazlarda doğrudan levan bulunduğu gösterilmiştir (Silbir vd., 2014). Silbir ve arkadaşlarının yaptığ1 çalışmada Z. mobilis ile levan üretimi koşulları optimize edilmiştir ve $299.1 \mathrm{~g} / \mathrm{L}$ başlangiç substrat (sakkaroz) konsantrasyonu, 42.3 saat inkübasyon süresi ve $\mathrm{pH} 6.0$ başlangiç değerinde maksimum levan konsantrasyonu olan 40.2 g/L'ye ulaşıldığı belirtilmiştir. Bacillus subtilis (Natto) Takahashi kullanılarak yapılan bir çalışmada $200 \mathrm{~g} / \mathrm{L}$ sakkaroz konsantrasyonu, 37 ${ }^{\circ} \mathrm{C}$ 'de $\mathrm{pH} 7.0$ değerinde 21 saat inkübasyon süresi sonunda $49.4 \mathrm{~g} / \mathrm{L}$ levan elde edildiği bildirilmiştir (Shih vd., 2005). İmmobilize B. subtilis (Natto) Takahashi kullanılarak da 72 saat inkübasyon süresinde $70.6 \mathrm{~g} / \mathrm{L}$ levan üretimi gerçekleştirildiği 
bildirilmiştir (Shih vd., 2010). Bacillus licheniformis NS032 kullanılan bir çalışmada 96 saat inkübasyon sonunda $47.8 \mathrm{~g} / \mathrm{L}$ levan elde edildiği (Kekez vd., 2015), Acetobacter xylinum NCIM 2526 kullanilarak da 60 saat sonunda $13.25 \mathrm{~g} / \mathrm{L}$ levan elde edildiği (Srikanth vd., 2015b) bildirilmiştir.

Mikroorganizmaların sakkaroz fermantasyonu sırasında levan üretmelerini sağlayan hücre dışına salg1ladıkları levansukraz enzimleridir.

Levansukrazlar, sakkarozu parçalayan ve açığa çıkan fruktozları şeker polimerlerine dönüştüren enzimlerdir. Bakteriler tarafından hücre dışına salgilanan levansukrazlar bakterinin yüksek sakkaroz konsantrasyonunda FOS ve levan polimerlerini sentezlemesini sağlar. Levansukrazlar mikrobiyal kökenlerine ve reaksiyon koşullarına bağlı olarak uzun levan polimerleri ya da FOS üretirler (Öner vd., 2016). Levansukraz enzimi çeşitli mikroorganizmalar tarafindan üretilir ve bunlardan $B$. subtilis (Chambert vd., 1974), Acetobacter diazotrophicus (Hernandez vd., 1995), Erwinia amylovora (Caputi vd., 2013), Pseudomonas syringaepathovar (Hettwer vd., 1995) ve Z. mobilis (Erdal vd., 2017; SantosMoriano vd., 2015) levansukrazları karakterize edilmiştir. Enzim aktivitesi için önemli değişkenler sakkaroz konsantrasyonu, $\mathrm{pH}$ ve sıcakliktır. Z. mobilis levansukrazının reaksiyon koşullarına bağlı olarak hem FOS hem de levan ürettiği bildirilmiştir. Yapılan çalışmada $4-40{ }^{\circ} \mathrm{C}$ arasındaki reaksiyonlar incelenmiş ve $4{ }^{\circ} \mathrm{C}$ 'de en yüksek levan verimi elde edildiği, sıcaklık yükseldikçe FOS üretiminin arttığ1 bildirilmiştir (Santos-Moriano vd., 2015). Başka bir çalışmada Z. mobilis levansukrazin pH 5.4 tamponda ve 45 ${ }^{\circ} \mathrm{C}$ 'de FOS aktivitesi olduğu gösterilmiştir (Erdal vd., 2017). B. subtilis levansukraz1 $\mathrm{pH}$ 6'da ve 22 ${ }^{\circ} \mathrm{C}$ 'de levan üretirken (Chambert vd., 1974), E. amylovora levansukrazi $\mathrm{pH} 6.5$ tamponda ve $37^{\circ} \mathrm{C}$ sicaklikta FOS üretmektedir (Caputi vd., 2013). Doğrudan saflaştırılmış levansukraz enzimlerinin kullanılmasıyla levan üretimi ile ilgili literatürde yapılmış çalışmalar mevcuttur. Örneğin $B$. subtilis'ten levansukraz üretimi ve enzimatik levan sentezi incelenmiştir. Artan protein konsantrasyonlarında levan üretiminin arttığ1 ve $1000 \mu \mathrm{g} / \mathrm{mL}$ enzim kullanılarak \%84 verimle levan üretilebileceği bildirilmiştir (Abdel-Fattah vd., 2005). Enzimatik levan üretimi; düşük yan ürün oluşmas1, üretimin kontrollü olmas1 ve istenilen sürede gerçekleşmesi nedeniyle avantajlıdır. Bu çalışmada Z. mobilis levansukraz enziminin eldesi ve ham enzim ile levan üretim koşulları araştırılmıştır.

\section{MATERYAL VE YÖNTEM \\ Materyal}

di-nitro salisilik asit (DNS) ve diğer bütün analitik safllktaki kimyasallar Sigma-Aldrich ya da Merck'ten temin edilmiştir.

\section{Mikroorganizma ve Üreme Koşulları}

Bu çalışmada kullanılan Z. mobilis NRRL B-14023 hücresi Agricultural Research Service Culture Collection (Peoria, USA)'dan temin edilmiştir. Mikroorganizma, taze stok besiyeri ortaminda (glukoz; $20 \mathrm{~g} / \mathrm{L}$, bacto peptone; $10 \mathrm{~g} / \mathrm{L}$, maya özütü; $10 \mathrm{~g} / \mathrm{L}) \quad 28{ }^{\circ} \mathrm{C}^{\prime}$ de 24 saat boyunca inkübasyona bırakılmış ve inkübasyon sonrası $\% 50$ gliserol ile karıştırılarak $\quad-86 \quad{ }^{\circ} \mathrm{C}$ 'de dondurularak saklanmıştır.

\section{Z. mobilis Levansukraz Fermantasyonu}

Taze stok besiyeri ortamında geliştirilen $Z$. mobilis, $\% 5(\mathrm{v} / \mathrm{v}$ ) oranında aşı kültür ortamına (sakkaroz; $50 \mathrm{~g} / \mathrm{L}$, maya özütü; $7 \mathrm{~g} / \mathrm{L}, \mathrm{K}_{2} \mathrm{HPO}_{4} ; 2.5 \mathrm{~g} / \mathrm{L}$, $\left(\mathrm{NH}_{4}\right)_{2} \mathrm{SO}_{4} ; 1.6 \mathrm{~g} / \mathrm{L}, \mathrm{MgSO}_{4} .7 \mathrm{H}_{2} \mathrm{O} ; 1 \mathrm{~g} / \mathrm{L}, \mathrm{pH}$ 5.0) ekilmiş ve $28{ }^{\circ} \mathrm{C}$ 'de 24 saat boyunca inkübasyona bırakılmıştır. İnkübasyon sonrasında aşı kültürden $\% 5(\mathrm{v} / \mathrm{v})$ oranında üretim ortamına (sakkaroz; 159 g/L, maya özütü; $2.5 \mathrm{~g} / \mathrm{L}$, $\mathrm{K}_{2} \mathrm{HPO}_{4} ; 2 \mathrm{~g} / \mathrm{L}, \quad\left(\mathrm{NH}_{4}\right)_{2} \mathrm{SO}_{4} ; 2 \mathrm{~g} / \mathrm{L}$, $\mathrm{MgSO}_{4} .7 \mathrm{H}_{2} \mathrm{O} ; 1 \mathrm{~g} / \mathrm{L}, \mathrm{pH}$ 4.91) inokülasyon yapılmıştır. Fermantasyon, içerisinde $200 \mathrm{~mL}$ üretim ortamı bulunan $1 \mathrm{~L}$ erlenlerde statik kültür olarak $30.3{ }^{\circ} \mathrm{C}^{\prime}$ de yapilmıştır. Fermantasyon süresince farklı zamanlarda örnek alınarak hücre yoğunluğu, protein miktarı ve levansukraz aktivitesi ölçülmüştür.

\section{Hücre Yoğunluğu}

Fermantasyon ortamındaki hücrelerin yoğunluğu Thermo Scientific Genesys 10S UV-VIS spektrofotometrede $600 \mathrm{~nm}$ dalga boyunda belirlenmiștir. 


\section{Ham Enzim Eldesi}

Hücre dışına salgılanan enzimin eldesi, hücre dış1 proteinlerin hücrelerden ayrilmasi yoluyla gerçekleşmiştir. Fermantasyon sonrasında hücrelerin uzaklaştırılması için iki farklı yöntem denenmiştir. Santrifugasyon yönteminde fermantasyon sonrasinda alınan üretim ortamlan $4{ }^{\circ} C^{\prime}$ de 6500 rpm'de 20 dakika santrifüj edilmiş ve temiz üst faz ham enzim olarak ayrilmıstır. Filtrasyon yönteminde ise fermantasyon sonras1 üst faz $0.22 \mu \mathrm{m}$ selüloz asetat filtreden geçirilmiş ve temiz alt faz ham enzim olarak ayrılmıştır.

\section{Enzim Aktivite Tayini}

Levansukraz aktivitesi, açığa çıkan indirgen şeker (glukoz ve fruktoz) ya da glukoz miktarinin ölçülmesiyle belirlenmiştir. İndirgen şeker miktarı Miller'ın DNS yöntemine göre belirlenmiştir (Miller, 1959). $250 \mu \mathrm{L}$ seyreltilmiş enzim örneği $0.5 \mathrm{M}$ sakkaroz içeren $750 \mu \mathrm{L}$ tampon A $(22 \mathrm{mM}$ sitrat-fosfat, $\mathrm{pH}$ 5.4) ile karıştırılmış ve $35^{\circ} \mathrm{C}$ su banyosunda 10 dakika inkübasyona bırakılmıştır. 3 mL DNS (3,5-di-nitro salisilik asit) çözeltisi eklendikten hemen sonra, örnek $100{ }^{\circ} \mathrm{C}$ su banyosunda 5 dakika boyunca kaynamaya bırakılmıstır. Oda sıcaklığına getirilen örneklerin 540 nm'deki absorbans değerleri GENESYS 10S UV-Vis spektrofotometre ile ölçülmüştür. Örnekteki indirgen şeker miktarı glukoz standart eğrisi kullanılarak hesaplanmıştır. Bir birim levansukraz aktivitesi, dakikada $1 \mu \mathrm{mol}$ indirgen şekeri açığa çıkaran enzim miktarı olarak tanımlanmıştır.

\section{Elektroforez}

Protein saflı̆̆1 ve moleküler kütlesi SDSpoliakrilamid jel elektroforezi ile belirlenmiştir (Laemmli, 1970). Hücrelerden ayrilan ham enzim liyofilize edilmiş ve elde edilen toz, tampon A'da çözülmüştür. Ultrafiltrasyon üniteleri (Amicon 500, NMWCO $10 \quad \mathrm{kDa})$ kullanilarak santrifugasyon ile 30 kat konsantre edilmiş, $\% 12$ akrilamid jelde yürütülmüş ve Coomassie Brilliant Blue G-250 ile boyanmıştır (Lawrence ve Besir, 2009).

\section{Zimogram}

Jel üzerinde enzim aktivitesi zimogram (P. O’Mullan vd., 1991) ile belirlenmiştir. $100 \mu \mathrm{g}$ protein içeren $40 \mu \mathrm{L}$ örnekler denatüre edici olmayan \%10’luk poliakrilamid jelde yürütülmüş $\% 5$ sakkaroz içeren tampon A ile gece boyu inkübasyona bırakılmıştır.

\section{Protein Tayini}

Protein miktarı Bradford yöntemi ile belirlenmiştir (Bradford, 1976). $200 \mu \mathrm{L}$ Bradford boya çözeltisi üzerine $4 \mu \mathrm{L}$ örnek ilave edilerek Thermo Scientific Multiscan Go sistemde 96 kuyulu plakalarda $595 \mathrm{~nm}$ dalga boyunda okuma yapılmışır. BSA ile oluşturulan standart eğri denklem kullanılarak protein miktarı hesaplanmıştır.

\section{Levan Üretimi ve Miktar Tayini}

Levan üretimi için 30 birim enzim $0.2 \mathrm{M}$ sakkaroz içeren tampon A (22 mM sitrat-fosfat, $\mathrm{pH}$ 5.4) ile karıştırılmıştır. Levan üretimi iki farklı sıcaklıkta $\left(15^{\circ} \mathrm{C}\right.$ ve $\left.25^{\circ} \mathrm{C}\right)$ su banyosunda, toplam $15 \mathrm{~mL}$ hacimde gerçekleştirilmiş ve farklı zaman aralıklarında örnek alınmışır. Reaksiyon sonucu oluşan levan miktarı iki farklı yöntem ile hesaplanmıştır. Doğrudan levan miktarı belirlenmesi için reaksiyonların 400 nm'deki bulanıklık değişimi takip edilmiştir (Vigants, vd., 2001). Ticari levan ile oluşturulan standart eğriler kullanilarak levan miktarı $\mathrm{g} / \mathrm{L}$ cinsinden hesaplanmıştır. Oluşan levan miktarının indirgen şeker cinsinden belirlenmesi için ise levan çöktürülmüss ve elde edilen levan çökeltisi $0.1 \mathrm{M}$ $\mathrm{HCl}$ asit ile $100{ }^{\circ} \mathrm{C}$ su banyosunda 1 saat boyunca hidroliz edilmiştir (Viikari, 1984). Açığa çıkan indirgen şeker DNS yöntemi ile fruktoz standart eğrisi kullanılarak hesaplanmıştır. Levansukrazın levan üretimine iyonik yük etkisinin belirlenmesi için farklı $\mathrm{NaCl}$ konsantrasyonları içeren tamponlarda reaksiyonlar yapılmıştır. Ayrıca EDTA ve $10 \mathrm{mM} \mathrm{MgCl} 2, \mathrm{KCl},\left(\mathrm{NH}_{4}\right)_{2} \mathrm{SO}_{4}, \mathrm{CaCl}_{2}$ ve $\mathrm{ZnSO}_{4} .7 \mathrm{H}_{2} \mathrm{O}$ iyonları varlığında da reaksiyonlar yapılmışır.

\section{BULGULAR VE TARTIŞMA}

\section{Z. mobilis B-14023 Üreme Eğrisi}

Fermantasyon ortamindan 0., 12., 24. ve 36. saatlerde örnek alınarak $600 \mathrm{~nm}$ dalga boyunda absorbans okunmuş ve en yüksek değer 36. saatte görülmüştür (Şekil 2). Bu sonuç Silbir ve ark. (2014) ile paralellik göstermektedir, mikroorganizma sayısının en yüksek olduğu saat 36.saat olarak belirtilmiştir. 


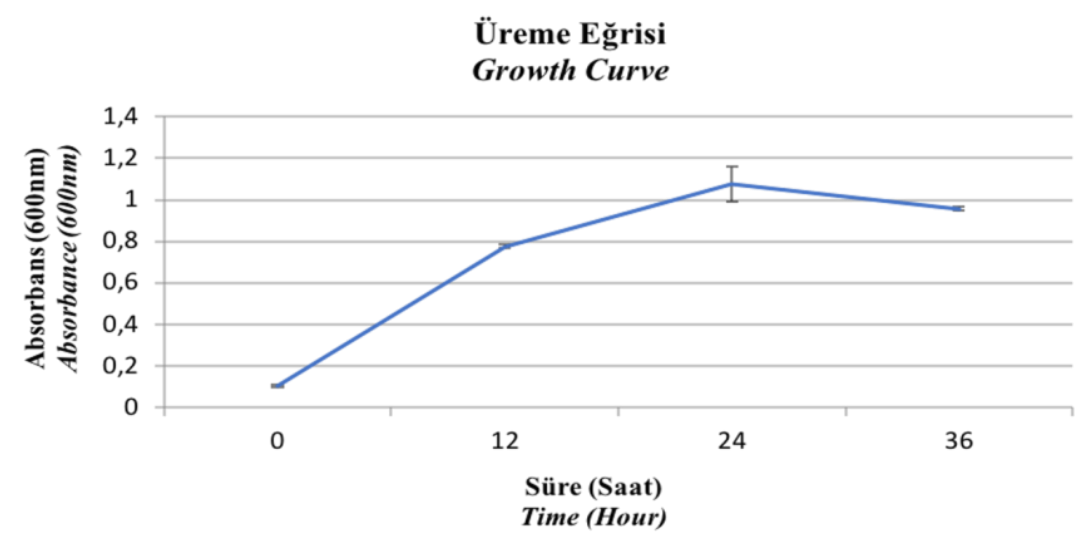

Şekil 2: Z. mobilis üreme eğrisi

Figure 2: Z. mobilis growth curve

\section{Z. mobilis Levansukraz Üretimine Sürenin Etkisi}

Fermantasyon sirasinda farklı saatlerde alınan örneklerden santrifüj yoluyla üst fazlar elde edilmiştir. Elde edilen üst fazlar elektroforez ile incelenmiş ve tek belirgin protein bandı olduğu görülmüsstür (Şekil 3). Ayrıca daha önce yapılan çalışma ile bu protein bandı sekanslanmış ve levansukraz olduğu doğrulanmıştır (Erdal vd., 2017). Levansukraz enzimi hücre dışı bir enzim olduğundan ve üst fazlarda levansukrazdan başka belirgin bir protein bandı görülmediğinden elde edilen üst faz ile enzim aktivite tayini yapılmıştır.

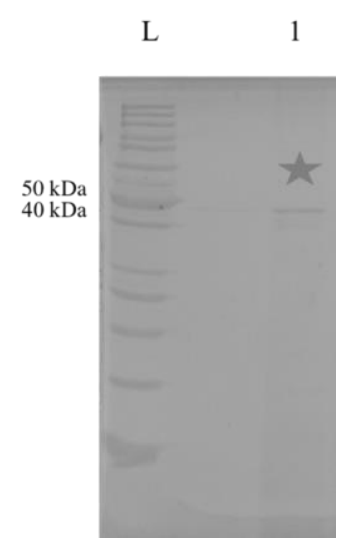

Şekil 3: Z. mobilis fermantasyon sonrası üst fazın $\% 12$ SDS-poliakrilamid jelde incelenmesi L: Protein ladder, 1: örnek. Levansukraz band1 yıldız ile işaretlenmiştir.

Figure 3: Analysis of cell free supernatant of Z. mobilis on 12\% SDS-polyacrylamide gel L: protein ladder, 1: sample. Levansucrase band is marked with a star.
Levansukraz enziminin hidroliz aktivitesinin belirlenmesi için indirgen şeker yöntemi kullanılmıştır ve enzimin en yüksek hidroliz aktivitesi değerinin 36. saatte bulunduğu görülmüştür (Şekil 4a). Hücrelerden ayrllmış üst fazdan toplam protein tayini yapilarak, protein miktarında artı̧s incelenmiştir. Fermantasyon süresince artan protein miktarı levansukraz miktarındaki artıştan kaynaklanmaktadır. Hidroliz aktivitesi sonuçlarıyla aynı şekilde en yüksek protein miktar1 36. saatte görülmüştür (Şekil 4b).

36 saat fermantasyon sonunda üst faz protein miktar1 $0.049 \pm 0.007 \mathrm{mg} / \mathrm{mL}$ ve hidroliz aktivitesi $10.07 \pm 1.3 \mathrm{mM}$ glukoz/dakika olarak hesaplanmıştır. Bu sonuçlar ışı̆̆ında inkübasyon süresi 36 saat olarak belirlenmiş̧ir.

\section{Levansukraz ile Levan Üretimi}

Ham enzim eldesi hücre dışı proteinlerin hücrelerden ayrılması yoluyla gerçekleşmiştir. Hücre dış1 proteinlerin hücrelerden ayrilması santrifugasyon ve filtrasyon ile gerçekleştirilmiş ve elde edilen ham enzim levan üretim denemelerinde kullanılmıştır. Reaksiyonlar sonucunda görülen beyaz bulanıklı̆̆ın levan olduğu bildirilmiştir (Vigants vd., 2001; Viikari, 1984). Yapilan ön denemede $25^{\circ} \mathrm{C}$ 'de 30 birim levansukraz ile $0.2 \mathrm{M}$ sakkaroz varlığında reaksiyon gerçekleştirilmiş ve 24 saat sonunda levan oluştuğu görülmüştür (Şekil 5a). Levan üretimi ayrıca zimogram ile de gösterilmiş ve jelde belirgin beyaz bir bant oluştuğu görülmüsstür (Şekil 5b). 


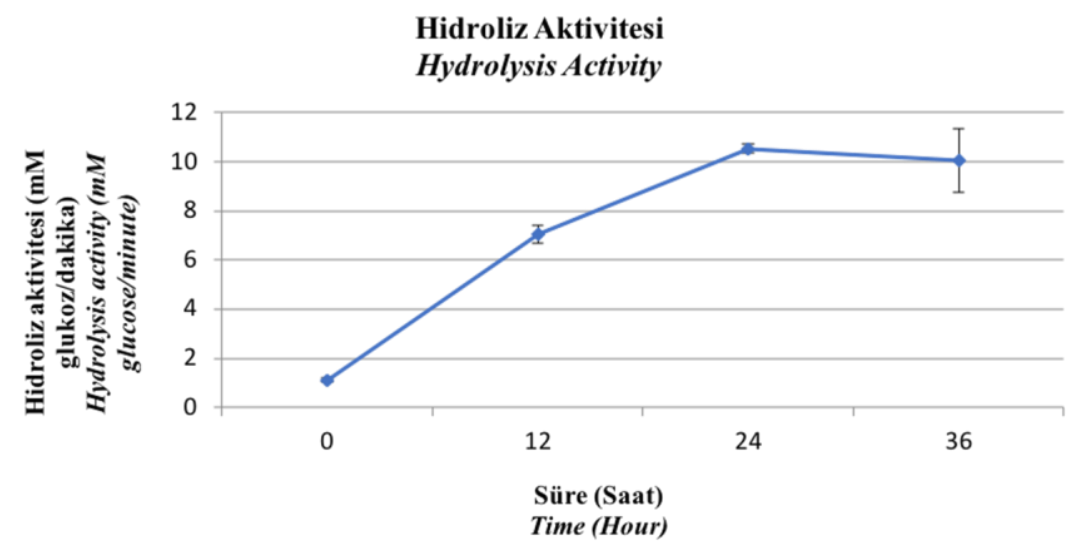

(a)

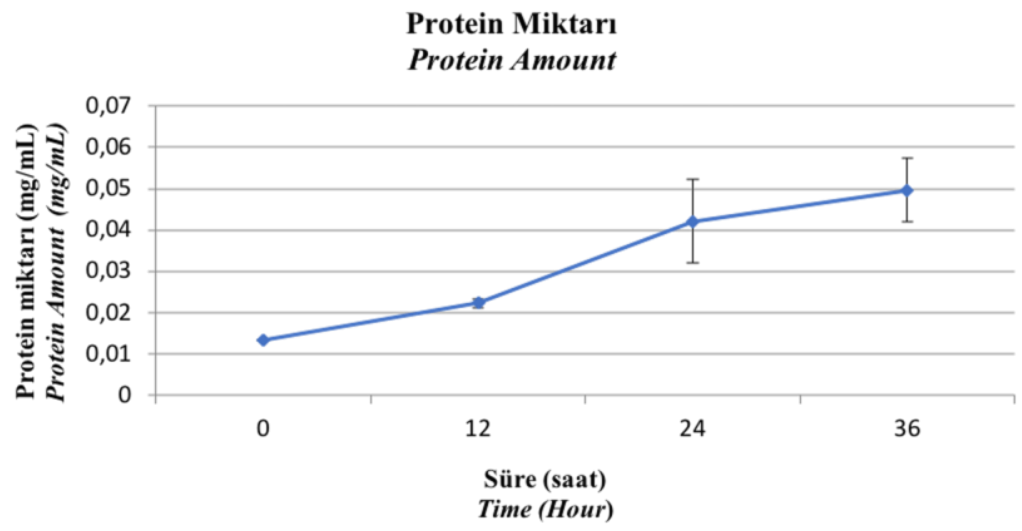

(b)

Şekil 4: Z. mobilis fermantasyon üst fazının (a) hidroliz aktivitesi ve (b) protein miktarı

Figure 4: Hydrolysis activity (a) and protein amount (b) of Z. mobilis fermentation supernatant

\section{Levan Üretimine Etki Eden Faktörler}

Reaksiyon Süresi ve Sucaklik

Levansukraz ile levan üretimi için optimum zaman ve sıcaklık koşullarını belirlemek amacıyla yapılan deneyler sonucunda artan süre ile levan üretiminin arttı̆̆1 gözlenmiştir (Şekil 6a). Bu çalışmada en fazla 24 saat reaksiyon yapılmış ve en yüksek levan miktarı 24. saatte elde edilmiştir. Reaksiyon için iki farklı sıcaklık denenmiş ve $Z$. mobilis levansukrazının $25{ }^{\circ} \mathrm{C}$ 'de daha yüksek miktarda levan ürettiği görülmüştür (Şekil 6b).

Literatürde yapılan bir çalışmada Z. mobilis CT2 levansukrazının optimum reaksiyon koşulunun $0.5 \mathrm{M}$ sakkaroz ve $50 \mathrm{mM}$ asetat $\mathrm{pH} 5.0$ tamponda
$25{ }^{\circ} \mathrm{C}$ 'de olduğu gösterilmiștir (Senthilkumar ve Gunasekaran, 2005). Bir başka çalışmada Z. mobilis UQM 2716 levansukrazin $0.16 \mathrm{M}$ sakkaroz 0.02 $\mathrm{M}$ sitrat fosfat $\mathrm{pH} 5.4$ tamponda levan aktivitesi için optimum sıcaklık $25^{\circ} \mathrm{C}$ olarak belirlenmiş ve $35{ }^{\circ} \mathrm{C}$ 'de aktivitenin görülmediği bildirilmiştir (Crittenden ve Doelle, 1994). Diğer bir çalışmada da E. colide üretilmiş rekombinant Z. mobilis ZMI levansukrazının levan üretimi için optimum sicaklığın $0{ }^{\circ} \mathrm{C}$ olduğu bildirilmiştir (Belghith, 1996). Hettwer ve ark., (1995) yaptıkları çalışmada $P$. syringae levansukazının en yüksek levan aktivitesini $18{ }^{\circ} \mathrm{C}^{\prime}$ de gösterdiğini bildirmiştir. Bacillus sp. TH4-2 levansukrazının levan aktivitesi için en uygun sıcaklığın $50^{\circ} \mathrm{C}$ olduğu bildirilmiştir (Ammar vd., 2002). 


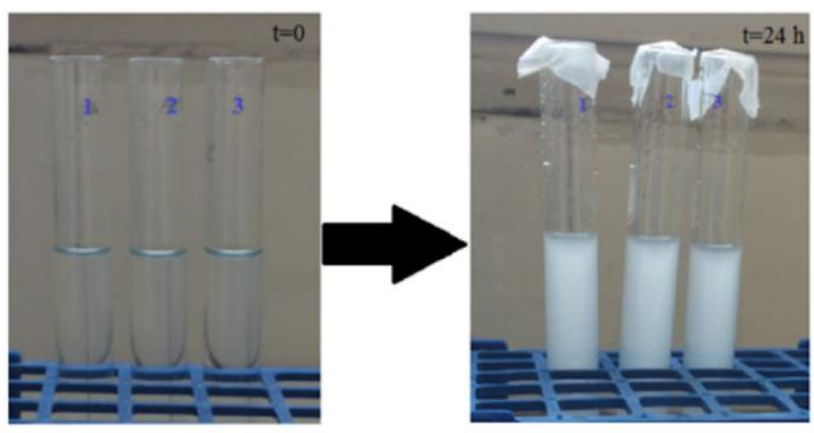

(a)

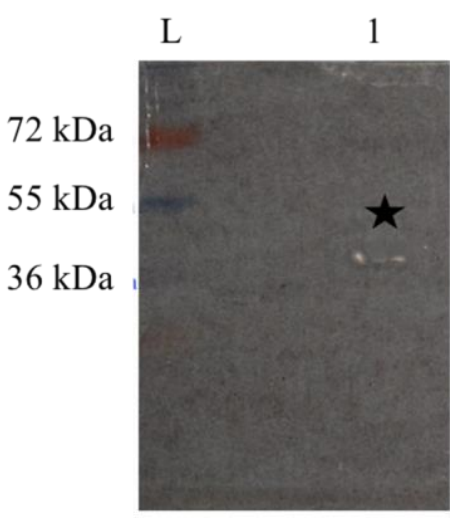

(b)

Şekil 5: (a) $t=0$ ve $t=24$ saat anında levan reaksiyon tüpleri (b) Zimogram analizi. L: Protein Ladder 1: örnek. Levansukraz bandı yıldız ile işaretlenmiştir.

Figure 5: Levan production in reactions tubes at $t=0$ and $t=24$ hours (a) and aymography (b) L: protein ladder, 1: sample. Levansucrase band is marked with a star.

\section{Enzimin Elde Edilme Yöntemi}

Levan reaksiyonları hem santrifugasyon hem de filtrasyon ile elde edilen ham enzim ile gerçekleştirilmiştir.

Elde edilen levan çözeltilerinin 400 nm'deki absorbans değerleri çok yakın bulunmuş (filtrasyon: 1,76; santrifugasyon: 1,66) daha kolay ve hızlı bir yöntem olduğu için çalışmalarda santrifugasyon yöntemi kullanılmıştır (Şekil 6c).

\section{İonik Yük, EDTA ve Metal İyonlar}

Z. mobilis levansukrazından levan üretimi için optimum inkübasyon süresi ve sicaklık belirlendikten sonra levan üretimini etkileyebilecek parametrelerden iyonik yük ve metal iyonları incelenmiştir. Reaksiyonlara farklı konsantrasyonlarda $\mathrm{NaCl}$, EDTA ve farklı metal iyonlar1 $\quad \mathrm{MgCl}_{2}, \mathrm{KCl}, \quad\left(\mathrm{NH}_{4}\right)_{2} \mathrm{SO}_{4}, \quad \mathrm{CaCl}_{2}$, $\mathrm{ZnSO}_{4} .7 \mathrm{H}_{2} \mathrm{O}$ ) eklenerek reaksiyonlar 30 birim levansukraz enzimi ile $25^{\circ} \mathrm{C}$ 'de 24 saat süreyle gerçekleştirilmiştir. Reaksiyonlar üç tekrar halinde gerçekleştirilmiş ve levan miktarı 400 nm'de spektrofotometrik olarak ölçülmüştür.

\section{İyonik Yük}

Sonuçlar artan $\mathrm{NaCl}$ konsantrasyonunun levan üretimini olumsuz etkilediğini göstermiştir (Şekil 7). $500 \mathrm{mM} \mathrm{NaCl}$ varllğında levan bulaniklik değerinde \%18.5'luk bir azalma gözlenmiştir. Bu sonuçlar literatürde daha önce yapılan çalışmalar ile farklılık göstermektedir. Vigants ve ark., (1998) yaptığ çalışmada Z. mobilis $113 \mathrm{~S}$ levansukrazı kullanılmış ve $0.4 \mathrm{M} \mathrm{NaCl}$ varllğında levan üretiminin kontrole kiyasla 1.2 kat arttığ bildirilmiştir. Trujillo Toledo ve ark., (2004) Gluconacetobacter diazotrophicus SRT4 levansukraz1 kullanarak yaptıkları çalısmada ise $0.1 \mathrm{M}$ sakkaroz varlığında $30^{\circ} \mathrm{C}$ 'de levan üretiminin artan $(0-1.2$ M) $\mathrm{NaCl}$ konsantrasyonu ile arttığ1 gösterilmiştir. $\mathrm{Bu}$ sonuçların farklılığ kullanılan farklı mikroorganizma türlerine ve diğer reaksiyon parametrelerine bağlı olarak açıklanabilir. 


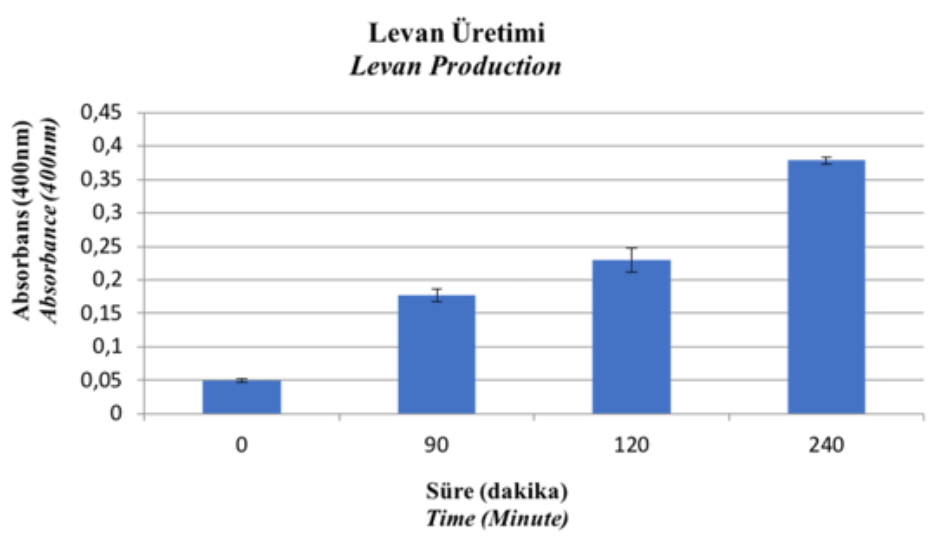

(a)

Levan Üretimi

Levan Production

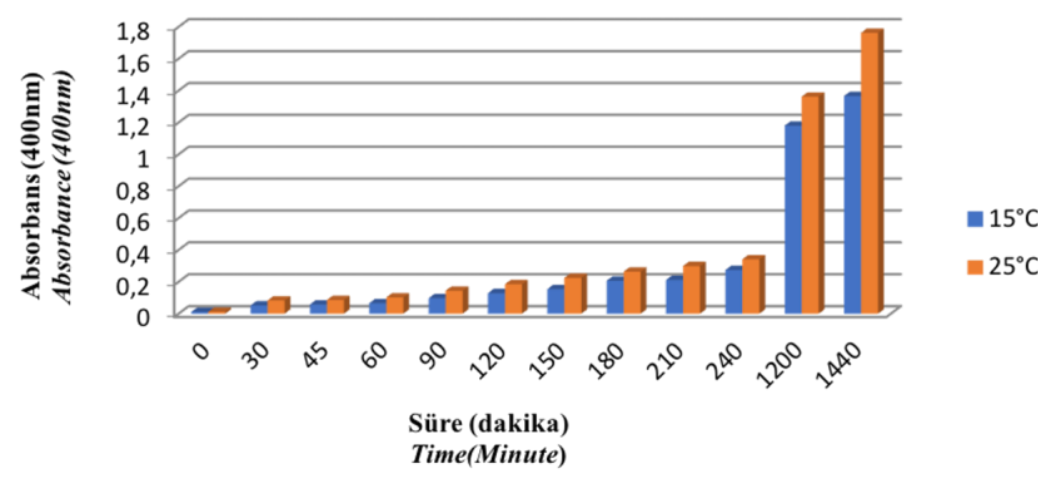

(b)

Levan Üretimi

Levan Production

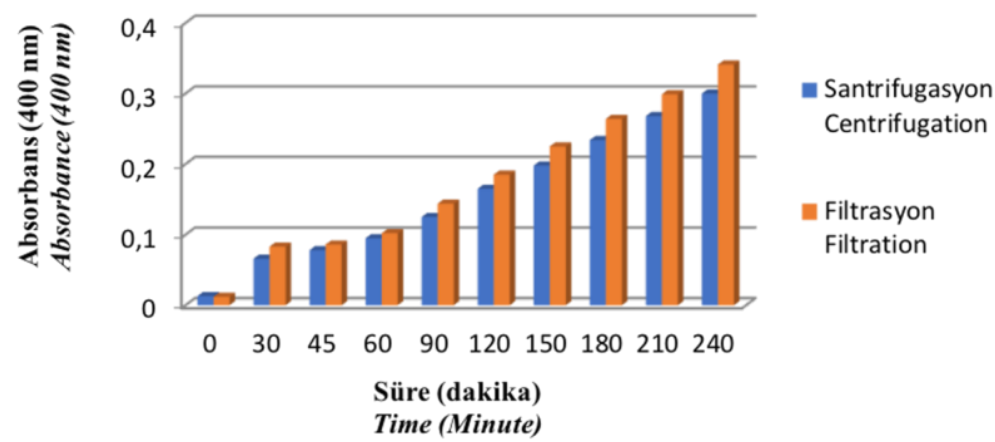

(c)

Şekil 6: (a) Farklı reaksiyon zamanlarında ve (b) farklı sıcaklıklarda levan üretimi (c) Filtrasyon ve santrifugasyon ile elde edilen ham levansukrazin $25^{\circ} \mathrm{C}$ 'de levan üretimi.

Figure 6: Levan production at different reaction time (a) and temperature (b). Levan production of levansucrase obtained by filtration and centrifugation at $25^{\circ} \mathrm{C}($ (c). 


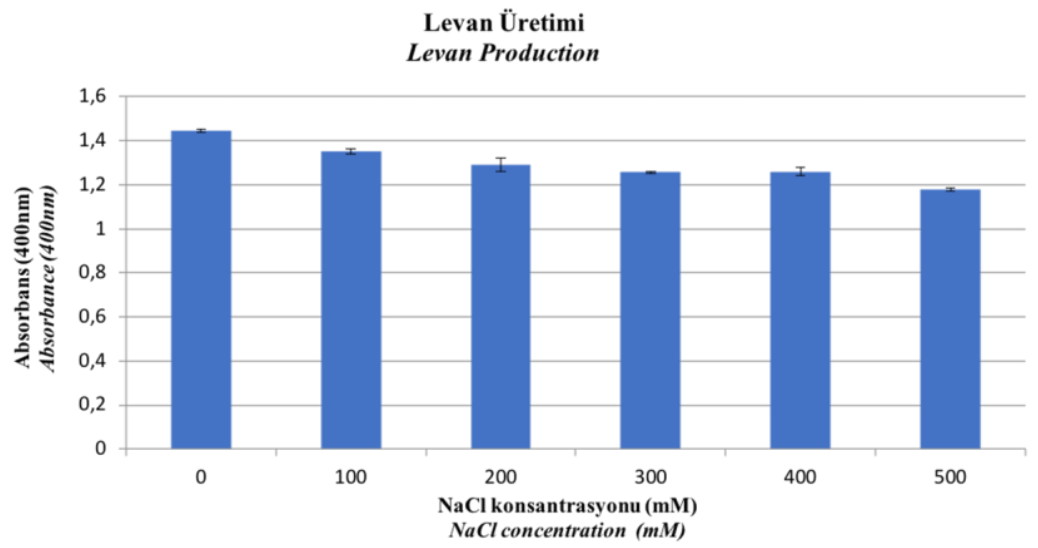

Şekil 7: Farklı $\mathrm{NaCl}$ konsantrasyonlarında $25^{\circ} \mathrm{C}$ 'de gerçekleştirilen levan reaksiyonlarının 24 saat sonundaki $400 \mathrm{~nm}$ absorbans değerleri.

Figure 7: $400 \mathrm{~nm}$ absorbance values of levan reactions with different $\mathrm{NaCl}$ concentrations. Reactions were done at $25{ }^{\circ} \mathrm{C}$ for 24 hours.

Metal Selat (EDTA)

Z. mobilis levansukrazının levan aktivitesi $1 \mathrm{mM}$ EDTA varlığında $\% 7$ ve $10 \mathrm{mM}$ EDTA varlığında \%18.5 azalmıștır (Șekil 8). Menéndez ve ark., (2002) G. diazotrophicus SRT 4 levansukrazını rekombinant olarak E. colide üretmiş ve $1 \mathrm{mM}$ EDTA varlığının levan aktivitesi üzerine etkisini incelemiş ve levan üretiminin yaklaşık $\% 5$ oranında azaldığını göstermiştir. Immobilize levansukraz-hidroksiapetit kompleksi ile yapılan bir çalıșmada, $1 \mathrm{mM}$ EDTA aktivitede \%2'lik bir azalmaya neden olmuştur (Jang, vd., 2000). Bu fark immobilize enzimin artan stabilitesi ile açılkanabilir.

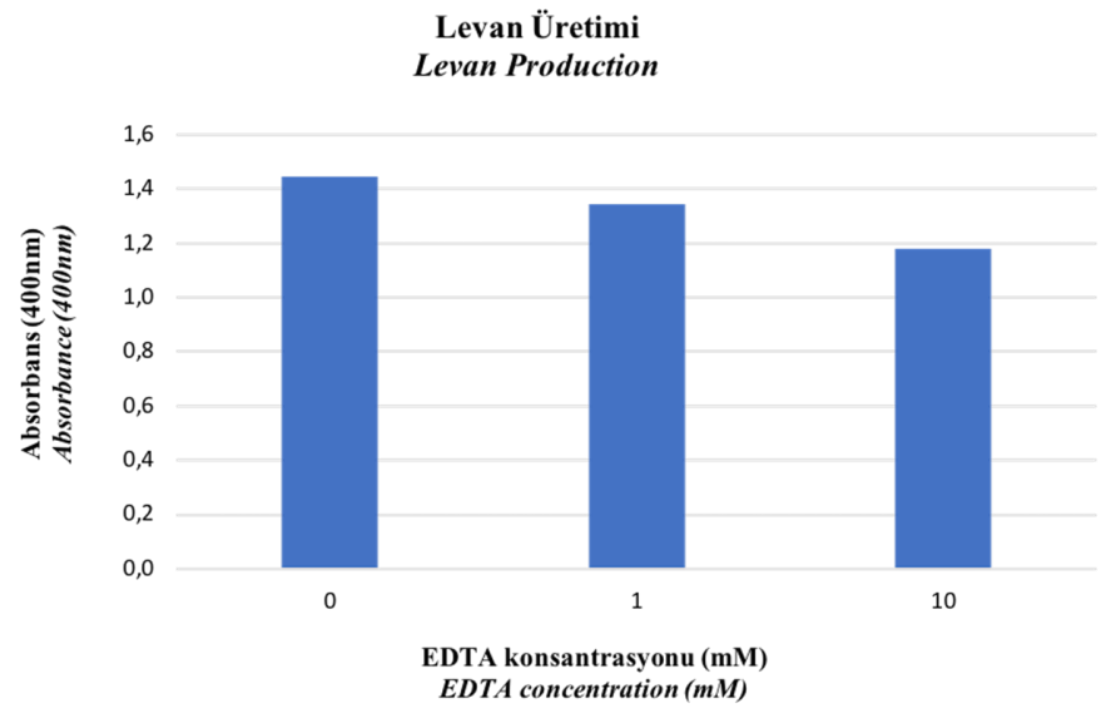

Şekil 8: Farklı EDTA konsantrasyonlarında $25^{\circ} \mathrm{C}$ 'de gerçekleștirilen levan reaksiyonlarının 24 saat sonudaki $400 \mathrm{~nm}$ absorbans değerleri.

Figure 8: $400 \mathrm{~nm}$ absorbance values of levan reactions in the presence of EDTA. Reactions were done at $25{ }^{\circ} \mathrm{C}$ for 24 bours. 


\section{Metal İyon}

$10 \mathrm{mM}$ EDTA varlı̆g Z. mobilis levansukrazının levan aktivitesinde önemli bir azalmaya neden olmuştur (Şekil 8). Bu sonuç Z. mobilis levansukrazının levan üretimi için metal iyonlarına gereksinimi olabileceğini göstermektedir. $\mathrm{Bu}$ sebeple farklı metal iyonları varlığında reaksiyonlar gerçekleştirilmiştir (Çizelge 1).

Çizelge 1: Farklı metal iyonlarının $10 \mathrm{mM}$

konsantrasyonda levan üretimine etkileri.

Table1: Effect of different metal ions $(10 \mathrm{mM})$ on levan production.

\begin{tabular}{lc}
\hline $\begin{array}{l}\text { Reaksiyon } \\
\text { Reactions }\end{array}$ & $\begin{array}{l}\text { Levan Üretimi (\%) } \\
\text { Levan Production (\%) }\end{array}$ \\
\hline Kontrol (Control) & 100 \\
$\mathrm{MgCl}_{2}$ & 68.2 \\
$\mathrm{KCl}$ & 93.52 \\
$\left(\mathrm{NH}_{4}\right)_{2} \mathrm{SO}_{4}$ & 85.05 \\
$\mathrm{CaCl}_{2}$ & 79.44 \\
$\mathrm{ZnSO}_{4} .7 \mathrm{H}_{2} \mathrm{O}$ & 94.77 \\
\hline
\end{tabular}

$10 \mathrm{mM} \mathrm{MgCl} 2, \mathrm{KCl},\left(\mathrm{NH}_{4}\right)_{2} \mathrm{SO}_{4}, \mathrm{CaCl}_{2}$ ve $\mathrm{ZnSO}_{4} .7 \mathrm{H}_{2} \mathrm{O}$ iyonları varliğında levan üretiminde bir miktar azalma gözlenmiştir, $\mathrm{MgCl}_{2}$ varlığındaki aktivite (\%68.2) diğerlerine göre daha düşük bulunmuştur (Şekil 9 ve Çizelge 1).

EDTA ile elde edilen sonuçlar (Şekil 8) ile birlikte değerlendirildiğinde, levan üretimine olumlu etki eden bir metal iyonun olduğu düşünülmüş ancak denenen iyonlar arasında tespit edilememiştir.

B. methylotrophicus SK 21.002 levansukrazi ile yapılan bir çalışmada $\mathrm{Ca}^{2+}, \mathrm{Na}^{+} \mathrm{K}^{+}$metal iyonlarının levan üretimi üzerine anlamlı bir etkiye sahip olmadığı, bununla birlikte $\mathrm{Cu}^{2+}, \mathrm{Fe}^{2+}$ ve $\mathrm{Zn}^{2+}$ iyonlarının levan oluşumunu inhibe ettiği gösterilmiştir. $\mathrm{Mg}^{2+}$ metal iyonunun ise kontrole göre aktiviteyi \%15 arttırdığı bildirilmiştir (Zhang vd., 2014). Çalışmada Z. mobilis'ten farklı bir mikroorganizma kullanıldığ için elde edilen farklı sonuçların mikroorganizma farkından kaynaklandığı düşünülmektedir.

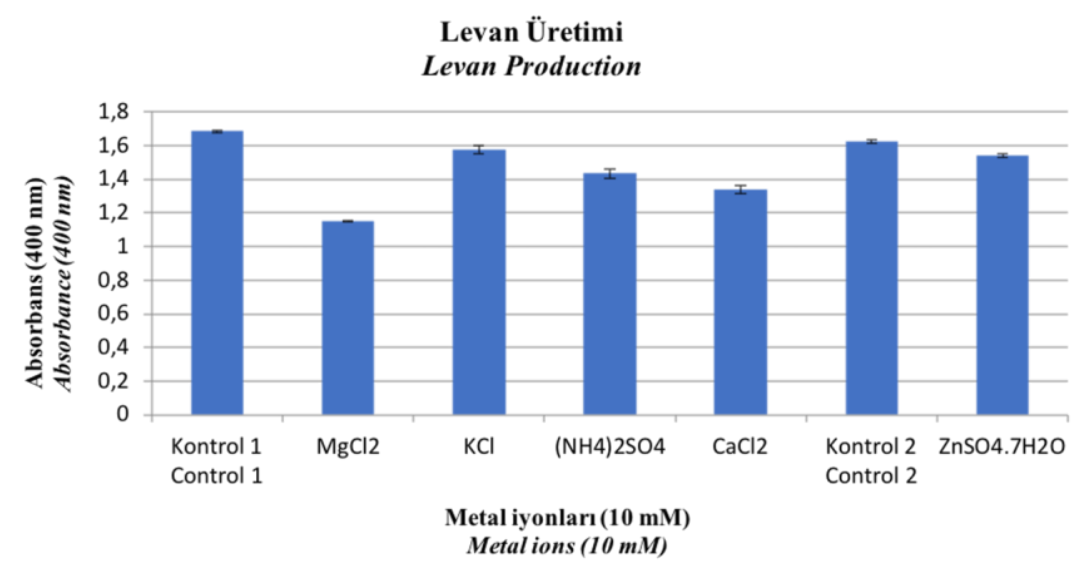

Şekil 9: Farklı metal iyonları varlı̆̆ında $25^{\circ} \mathrm{C}$ 'de gerçekleştirilen levan reaksiyonlarının 24 saat sonundaki $400 \mathrm{~nm}$ absorbans değerleri.

Figure 9: $400 \mathrm{~nm}$ absorbance values of levan reactions in the presence of different metal ions. Reactions were done at 25 ${ }^{\circ} \mathrm{C}$ for 24 hours.

Z. mobilis levansukraz ile yapılan bir çalışmada, farklı iyonlar içeren çözeltilerin bulunduğu reaksiyonlar $37^{\circ} \mathrm{C}$ 'de 60 dakika inkübe edilerek hidroliz aktivitesi üzerindeki etkisi incelenmiştir. 1 $\mathrm{mM}$ konsantrasyonda $\mathrm{K}^{+}$ve $\mathrm{Na}^{+}$iyonlarının kontrole göre aktiviteyi $\% 5$ ve $\% 2$ arttırdığ , ancak metal iyonlarının konsantrasyonunun artması ile aktivitenin azaldığ1 bildirilmiştir. $\mathrm{Ca}^{2+}$ iyonu varlığında sirasıyla $1 \mathrm{mM}, 5 \mathrm{mM}$ ve $10 \mathrm{mM}$ çözeltilerde $\% 25, \% 33$ ve $\% 36$ artış gözlenmiştir. $\mathrm{Zn}^{2+}$ iyonu ile yapilan deneyde ise artan konsantrasyonda, aktivitede $\% 3, \% 8$ ve $\% 10$ azalış gözlenmiştir (Shaheen vd., 2017). Literatürde Z. mobilis levansukrazının metal iyon 
varllğında levan üretim aktivitesi ile ilgili yapılan çalışmaya rastlanmamıstır. Levan üretiminin ve hidroliz aktivitesinin farklı mekanizmaları olduğu yapıs1 çözülen E. amylovora levansukrazında gösterilmiştir (Wuerges vd., 2015). Ayrıca Z. mobilis levansukrazı ile yapilan yap1 modellemesi çalışmasında da hidroliz aktivitesi ve levan üretiminde enzimin farklı bölgelerinin aktif rol oynadığı gösterilmiştir (Bakar ve Kaplan-Türköz, 2017). Metal iyonlanın hidroliz ve levan aktivitesi üzerine farklı etki göstermesinin sebebinin, reaksiyon mekanizmalarındaki farktan kaynaklandığı düşünülmektedir.

\section{Levan Verimi}

Levan miktarının belirlenmesi için iki farklı yöntemle hesaplama yapılmıştır.

Oluşan levanın fruktoz içeriğinin belirlenmesine dayanan yönteme göre levan çöktürülmüss, asit hidrolizi ile parçalanmış ve indirgen şeker tayin yöntemiyle levan miktarı $69.159 \mathrm{mg}$ fruktoz/mL olarak hesaplanmıştır. Levan miktarı için kullanılan diğer yöntemde ise levan miktarı 400 nm'deki absorbans değeri ve oluşturulan levan standart eğrisi kullanılarak hesaplanmıştır. Bu yöntemle 24 saat reaksiyon sonunda $62.42 \pm 0.28$ $\mathrm{g} / \mathrm{L}$ levan oluştuğu hesaplanmıştır, bu değer literatür ile karşılaştırıldığında yüksektir. Literatürde rekombinant $Z$. mobilis levansukrazlar1 ile çalışmalar yapılmıştır. Chiang vd., (2009) 10 $\mathrm{mL} \% 200.5 \mathrm{M}$ sakkaroz $100 \mathrm{mM}$ sodyum asetat $\mathrm{pH} 5.0$ tamponda reaksiyon hazırlanmış ve 15 ${ }^{\circ} \mathrm{C}$ 'de 9 saat inkübasyon sonrası $53 \mathrm{~g} / \mathrm{L}$ levan elde edildiği bildirilmiş̧ir. Diğer bir çalışmada $50 \mathrm{mM}$ asetat $\mathrm{pH} 5.0$ tamponda $\% 20$ sakkaroz kullanılmış ve $0{ }^{\circ} \mathrm{C}$ 'de 70 saat inkübasyon sonras1 $50 \mathrm{~g} / \mathrm{L}$ levan elde edilmiştir (Belghith, 1996).

\section{SONUÇ}

Bu çalışmada Z. mobilis kullanılarak levansukraz enzimin eldesi ve elde edilen enzim ile levan üretimi başarıyla gerçekleştirilmiştir. Levan gıda ve diğer birçok farklı endüstride prebiyotik, yağ ikamesi, antioksidan ve biyofilm oluşturma gibi özellikleri sayesinde kullanım alanına sahiptir. Levanın bu geniş endüstriyel uygulamalarına rağmen büyük ölçekte üretimleri için yeni yöntemler aranmaktadır. Levanın ekonomik olarak üretilebilmesi için yeni stratejiler gerekmektedir.

Bu çalışmada levan üretimi için ham levansukraz enzimi kullanılmış ve levan üretimi için optimum süre ve sicaklik $25{ }^{\circ} \mathrm{C}^{\prime}$ de 24 saat olarak bulunmuştur. $\mathrm{Bu}$ üretim süresi ve sicaklikta ortalama $62.42 \pm 0.28 \mathrm{~g} / \mathrm{L}$ levan üretimi gerçekleştirilmiştir.

Levan üretimi gerçekleştirildikten sonra üretime etki eden faktörler incelenmiştir ve $10 \mathrm{mM}$ EDTA, $10 \mathrm{mM} \mathrm{MgCl}$ varlığında ve $\operatorname{artan} \mathrm{NaCl}$ konsantrasyonlannda üretilen levan miktarında azalma olduğu bulunmuştur.

$\mathrm{Bu}$ çalışmayla Z. mobilis NRRL B-14023 hücrelerinden üretilen levansukraz enziminin levan üretiminde kullanılabileceği ilk kez gösterilmiş olduğundan literatüre önemli katkı sağlayacağ1 düşünülmektedir. Ayrıca ham enzim ile maliyetli saflaştırma işlemlerine gerek kalmadan ve oda sıcaklığında verimli levan üretimi yapılabileceği gösterilmiştir. Bütün bunlar büyük ölçek üretimin uygulanabilir olduğunu göstermektedir. Üretimin endüstriye uygulanmas1 ve üretilen levanın özelliklerinin incelenmesi önerilmektedir.

\section{TEŞEKKÜR}

$\mathrm{Bu}$ çalışma "Zymomonas mobilis levansukraz enziminin üretilmesi, saflaştırılması, karakterizasyonu ve endüstriyel kullanımı" başlıklı TÜBİTAK-TOVAG (proje no: 214O174) proje kapsamında desteklenmiştir.

\section{KAYNAKÇA}

Abdel-Fattah, A. F., Mahmoud, D. A. R., Esawy, M. A. T. (2005). Production of levansucrase from Bacillus subtilis NRC 33a and enzymic synthesis of levan and fructo-oligosaccharides. Curr Microbiol, 51(6), 402-407, doi:10.1007/s00284-005-0111-1.

Arvidson, S. A., Rinehart, B. T., Gadala-Maria, F. (2006). Concentration regimes of solutions of levan polysaccharide from Bacillus sp. Carbohydr Polym, 65(2), 144-149, doi: 10.1016/j.carbpol. 2005.12.039. 
AU - Lawrence, A.-M., AU - Besir, H. (2009). Staining of Proteins in Gels with Coomassie G250 without Organic Solvent and Acetic Acid. JoVE, (30), e1350, doi:10.3791/1350.

Bakar, B., Kaplan-Türköz, B. (2017). Structural Modelling and Structure-Function Analysis of Zymomonas mobilis Levansucrase. SDÜ Fen Bil Enst Der, 21(1), 279, doi: 10.19113/sdufbed.81065.

Bekers, M., Upite, D., Kaminska, E., Laukevics, J., Grube, M., Vigants, A., Linde, R. (2005). Stability of levan produced by Zymomonas mobilis. Process Biochem, 40(5), 1535-1539, doi: 10.1016/j.procbio.2004.01.052.

Belghith, H. (1996). Optimal conditions for levan formation by an overexpressed recombinant levansucrase. Biotechnol Lett, 18(4), 467-472, doi: 10.1007/BF00143472.

Ben Ammar, Y., Matsubara, T., Ito, K., Iizuka, M., Limpaseni, T., Pongsawasdi, P., Minamiura, N. (2002). Characterization of a thermostable levansucrase from Bacillus sp. TH4-2 capable of producing high molecular weight levan at high temperature. J Biotechnol 99(2), 111-119, doi: 10.1016/S0168-1656(02)00160-8.

Bradford, M. M. (1976). A rapid and sensitive method for the quantitation of microgram quantities of protein utilizing the principle of protein-dye binding. Anal Biochem, 72(1-2), 248254, doi: 10.1016/0003-2697(76)90527-3.

Caputi, L., Nepogodiev, S. A., Malnoy, M., Rejzek, M., Field, R. A., Benini, S. (2013). Biomolecular characterization of the levansucrase of Ervinia amylovora, a promising biocatalyst for the synthesis of fructooligosaccharides. J Agric Food Chem, 61(50), 12265-12273, doi: $10.1021 /$ jf4023178.

Chambert, R., Gonzy-Treboul, G., Dedonder, R. (1974). Kinetic Studies of Levanosucrase of Bacillus subtilis. Eur J Biochem 41, 285-300, doi: 10.1111/j.1432-1033.1974.tb03269.x.

Chiang, C. J., Wang, J. Y., Chen, P. T., Chao, Y. P. (2009). Enhanced levan production using chitin-binding domain fused levansucrase immobilized on chitin beads. Appl Microbiol
Biotechnol, 82(3), 445-451, doi: 10.1007/s00253008-1772-z.

Crittenden, R. G., Doelle, H. W. (1994). Identification and Characterization of the Extracellular Sucrases of Zymomonas mobilis Uqm2716 (Atcc-39676). Appl Microbiol Biotechnol, 41(3), 302-308, doi: 10.1007/BF00221223.

Erdal, Ö., Kaplan-Türköz, B., Taştan, Ö., Göksungur, Y. (2017). Levansucrase production by Zymomonas mobilis: Optimization of process parameters and fructooligosaccharide production. J Food Biochem, 41(3), 1-9, doi: 10.1111/jfbc.12361.

Ergene, E., Avc1, A. (2016). Mikrobiyel ekzopolisakkaritler. SAÜ Fen Bil Der, 20(2), 193202.

Hernandez, L., Arrieta, J., Menendez, C., Vazquez, R., Coego, A., Suarez, V.,Chambert, R. (1995). Isolation and enzymic properties of levansucrase secreted by Acetobacter diazotrophicus SRT4, a bacterium associated with sugar cane. Biochem J, 309(1), 113-118, doi: 10.1042/ bj3090113.

Hettwer, U., Gross, M., Rudolph, K. (1995). Purification and characterization of an extracellular levansucrase from Pseudomonas syringae pv. phaseolicola. J Bacteriol, 177(10), 28342839, doi: 10.1128/jb.177.10.2834-2839.1995.

Jakob, F., Meißner, D., Vogel, R. F. (2012). Comparison of novel GH 68 levansucrases of levan-overproducing Gluconobacter species. Acetic Acid Bacteria, 1(1), 2, doi: 10.4081/aab.2012.e2.

Jang, K., Song, K., Kim, J., Kim, H., Chung, B., Rhee, K. (2000). Production of levan using recombinant levansucrase immobilized on hydroxyapatite. Bioprocess Eng 23: 89, doi: 10.1007/s004499900153.

Kekez, B. D., Gojgic-Cvijovic, G. D., Jakovljevic, D. M., Stefanovic Kojic, J. R., Markovic, M. D., Beskoski, V. P., Vrvic, M. M. (2015). High Levan Production by Bacillus licheniformis NS032 Using Ammonium Chloride as the Sole Nitrogen Source. Appl Biochem Biotechnol, 175(6), 3068-3083, doi: 10.1007/s12010-015-1475-8.

Ki-hyo, J., Kang, S. A., Cho, Y., Kim, Y., Lee, Y.J., Hong, K., Choue, R. W. (2003). Prebiotic 
Properties of Levan in Rats. J. Microbiol. Biotechnol, 13(3), 348-353.

Laemmli, U. K. (1970). Cleavage of Structural Proteins during the Assembly of the Head of Bacteriophage T4. Nature, 227, 680, doi: 10.1038/227680a0.

Menéndez, C., Hernández, L., Selman, G., Mendoza, M. F., Hevia, P., Sotolongo, M., Arrieta, J. G. (2002). Molecular cloning and expression in Escherichia coli of an exo-levanase gene from the endophytic bacterium Gluconacetobacter diazotrophicus SRT4. Curr Microbiol, 45(1), 5-12, doi: 10.1007/s00284-001-0044-2.

Miller, G. L. (1959). Use of Dinitrosalicylic Acid Reagent for Determination of Reducing Sugar. Anal Chem, 31(3), 426-428, doi: 10.1021/ac60147a030.

Öner, E. T., Hernández, L., Combie, J. (2016). Review of Levan polysaccharide: From a century of past experiences to future prospects. Biotechnol $A d v$, 34(5), 827-844, doi: 10.1016/j.biotechadv. 2016.05.002.

P. O’Mullan, M. S.-D. and D. E. E. (1991). Identification of Saccharolytic Enzymes of Zymomonas mobilis CP4, 13(2), 137-142.

Ritsema, T., Smeekens, S. (2003). Fructans: Beneficial for plants and humans. Curr Opin Plant Biol, 6(3), 223-230, doi: 10.1016/S13695266(03)00034-7.

Roberfroid, M. B. (2000). Prebiotics and probiotics: are they functional foods? The American Journal of Clinical Nutrition, 71(6), 1682S7S; discussion 1688S-90S, doi: 10.1093/ajcn/71.6.1682S.

Roberts, E.J., Garegg, P. J. (1998). Levan derivatives, their preparation, composition and applications includingmedical and food applications. World patent appl., WO9803184.

Santos-Moriano, P., Fernandez-Arrojo, L., Poveda, A., Jimenez-Barbero, J., Ballesteros, A. O., Plou, F. J. (2015). Levan versus fructooligosaccharide synthesis using the levansucrase from Zymomonas mobilis: Effect of reaction conditions. J Mol Catal B Ensym, 119, 1825, doi: 10.1016/j.molcatb.2015.05.011.
Senthilkumar, V., Gunasekaran, P. (2005). Influence of fermentation conditions on levan production by Zymomonas mobilis CT2. Indian J Biotechnol, 4(4), 491-496.

Shaheen, S., Aman, A., Siddiqui, N. N. (2017). Influence of Metal ions, Surfactants and Organic Solvents on the Catalytic Performance of Levansucrase from Zymomonas mobilis. Journal of Basic and Applied Sciences, 13,41-46.

Shih, I. L., Chen, L. D., Wang, T. C., Wu, J. Y., Liaw, K. S. (2010). Tandem production of levan and ethanol by microbial fermentation. Green Chemistry, 12(7), 1242-1247, doi: 10.1039/ b924765c.

Shih, I. L., Yu, Y. T., Shieh, C. J., Hsieh, C. Y. (2005). Selective production and characterization of levan by Bacillus subtilis (Natto) Takahashi. J Agric Food Chem, 53(21), 8211-8215, doi: 10.1021/jf058084o.

Silbir, S., Dagbagli, S., Yegin, S., Baysal, T., Goksungur, Y. (2014). Levan production by Zymomonas mobilis in batch and continuous fermentation systems. Carbohydr Polym, 99, 454461, doi: 10.1016/j.carbpol.2013.08.031.

Srikanth, R., Reddy, C. H. S. S. S., Siddartha, G., Ramaiah, M. J., Uppuluri, K. B. (2015a). Review on production, characterization and applications of microbial levan. Carbobydr Polym, 120, 102-114, doi: 10.1016/j.carbpol.2014.12.003.

Srikanth, R., Siddartha, G., Sundhar Reddy, C. H. S. S., Harish, B. S., Janaki Ramaiah, M., Uppuluri, K. B. (2015b). Antioxidant and anti-inflammatory levan produced from Acetobacter xylinum NCIM2526 and its statistical optimization. Carbohydr Polym, 123, 8-16, doi: 10.1016/j.carbpol. 2014.12.079.

Srikanth, S., Swathi, M., Tejaswini, M., Sharmila, G., Muthukumaran, C., Jaganathan, M. K., Tamilarasan, K. (2014). Statistical optimization of molasses based exopolysaccharide and biomass production by Aureobasidium pullulans MTCC 2195. Biocatalysis and Agricultural Biotechnology, 3(3), 7-12, doi: 10.1016/j.bcab.2013.11.011.

Trujillo Toledo, L. E., Gómez Riera, R., Banguela Castillo, A., Soto Romero, M., Arrieta Sosa, J. G., 
Hernández García, L. (2004). Catalytical properties of N-glycosylated Gluconacetobacter diazotrophicus levansucrase produced in yeast. Electron J Biotechnol, 7(2), 0-0, doi: 10.2225/vol7issue2-fulltext-4.

Vigants, A., Hicke, H.-G., Marx, S. P. (2001). A Simple and Efficient Method for the Purification of Membrane-Bound Levansucrase from Zymomonas mobilis. Curr Microbiol, 42(6), 415-418, doi: $10.1007 / \mathrm{s} 002840010239$.

Vigants, A., Kruce, R., Bekers, M., Zikmanis, P. (1998). Response of Zymomonas mobilis levansucrase activity to sodium chloride. Biotechnol Lett, 20(11), 1017-1019, doi: 10.1023/ A:1005454921301.

Viikari, L. (1984). Formation o f levan and sorbitol from sucrose by Zymomonas mobilis, Appl Microbiol Biotechnol, 19: 252, doi: 10.1007/BF00251846.
Vijayendra, S. V. N., Shamala, T. R. (2014). Film forming microbial biopolymers for commercial applications-A review. Crit Rev Biotechnol, 34(4), 338-357, doi: 10.3109/07388551.2013.798254.

Wuerges, J., Caputi, L., Cianci, M., Boivin, S., Meijers, R., Benini, S. (2015). The crystal structure of Erwinia amylovora levansucrase provides a snapshot of the products of sucrose hydrolysis trapped into the active site. J Struct Biol, 191(3), 290-298, doi: 10.1016/j.jsb.2015.07.010.

Xiao, M., Feng, F., Lu, L. (2014). Preparation method of levan-contained yogurt. Chinese patent CN103190478B.

Zhang, T., Li, R., Qian, H., Mu, W., Miao, M., Jiang, B. (2014). Biosynthesis of levan by levansucrase from Bacillus methylotrophicus SK 21.002. Carbohydr Polym 101(1), 975-981, doi: 10.1016/j.carbpol.2013.10.045. 